\title{
The Demand for Hospital Emergency Services: Trends during the First Month of COVID-19 Response
}

\author{
Rui Santana ${ }^{a, b}$ Joana Santos Sousa ${ }^{c}$ Patrícia Soares ${ }^{a, b}$ Sílvia Lopes ${ }^{a, b}$ \\ Paulo Boto ${ }^{a, b}$ João Victor Rocha ${ }^{a, b}$ \\ a Public Health Research Center, NOVA National School of Public Health, Universidade NOVA de Lisboa, \\ Lisbon, Portugal; ${ }^{b}$ Comprehensive Health Research Center, Universidade NOVA de Lisboa, Lisbon, Portugal; \\ 'NOVA National School of Public Health, Universidade NOVA de Lisboa, Lisbon, Portugal
}

\section{Keywords \\ Emergency care $\cdot$ COVID-19 · Portugal}

\begin{abstract}
Introduction: Since December 2019, more than 925,000 cases of COVID-19 have been reported worldwide, 8,251 cases in Portugal by the end of March. Previous studies related to the SARS pandemic showed a decrease up to $80 \%$ in the emergency care episodes. Hence, the objective of this study is to analyze the use of emergency services during the first pandemic month, compared to historical records. Methods: Data from emergency episodes in mainland Portugal, from January 2014 to March 2020, were downloaded from the National Health Service (NHS) Transparency Portal and the NHS monitoring website. The evolution of emergency services from March to September 2020 was forecasted based on historical data from January 2014 to February 2020. Information for March 2020 was forecasted globally, by the Regional Health Administration (RHA) and Manchester Triage System (MTS). Results: Compared with forecasted values, there was a $48 \%$ reduction in the number of emer-
\end{abstract}

gency episodes in March 2020. In the analysis by the RHA, Alentejo had the smallest decrease in the number of episodes; interestingly, Alentejo is also the area with fewer COVID-19 cases in mainland Portugal. In the analysis by the MTS, the episodes classified as yellow showed the highest reduction (50\%). For episodes classified as urgent, there is a difference of about 144,000 episodes during March 2020. Discussion: The results of this preliminary study are aligned with the evidence produced for previous pandemics. Data about the use of emergency services, demographic and clinical characteristics of the episodes would be relevant to analyze this reduction. Conclusion: There was a significant drop in the number of emergency service use in March 2020, and although the causes of this reduction are not determined, the association between the beginning of the pandemic and the reduction of demand is evident. Understanding this phenomenon is crucial to plan interventions to avoid unnecessary morbidities or deaths, caused by a delayed visit to the emergency department.

(c) 2020 The Author(s). Published by S. Karger AG, Basel on behalf of NOVA National School of Public Health

\section{Karger ${ }^{\prime \prime}$}

karger@karger.com www.karger.com/pjp

Karger Open access
(C) 2020 The Author(s). Published by S. Karger AG, Basel on behalf of NOVA National School of Public Health

This article is licensed under the Creative Commons AttributionNonCommercial-NoDerivatives 4.0 International License (CC BYNC-ND) (http://www.karger.com/Services/OpenAccessLicense) Usage and distribution for commercial purposes as well as any distribution of modified material requires written permission.
Rui Santana

Escola Nacional de Saúde Pública, Universidade NOVA de Lisboa Av. Padre Cruz

PT-1600-560 Lisbon (Portugal)

RuiSantana@ensp.unl.pt 


\section{A procura de serviços de urgência hospitalar: tendências durante o primeiro mês de resposta à COVID-19}

\author{
Palavras Chave \\ Urgência hospitalar $\cdot$ COVID-19 $\cdot$ Portugal
}

\section{Resumo}

Introdução: Desde dezembro 2019 foram reportados mais de 925,000 casos de COVID-19 no mundo, 8,251 dos quais em Portugal até final de março. Estudos anteriores relacionados com a pandemia SARS mostraram uma redução de $80 \%$ nos episódios de urgência. Assim, o objetivo deste estudo é analisar a utilização dos serviços de urgência durante o primeiro mês de pandemia, comparando com registos históricos. Métodos: Dados de episódios de urgência de Portugal continental, de janeiro 2014 a março 2020, foram extraídos do Portal da Transparência do SNS e do website de monitorização do SNS. A evolução do número de urgências de março a setembro 2020 foi estimada considerando os dados históricos de janeiro 2014 a fevereiro 2020. A informação de março 2020 foi estimada globalmente, por Administração Regional de Saúde (ARS) e pelo Sistema de Triagem de Manchester (STM). Resultados: Comparando com valores previstos, verificou-se uma redução de $48 \%$ no número de episódios de urgência em março 2020. Analisando por ARS, Alentejo registou a menor redução neste número, e curiosamente o Alentejo é também a área com menos casos de COVID-19 em Portugal continental. Na análise por STM, os episódios amarelos registaram a maior redução (50\%). Nos episódios urgentes registou-se uma diferença de cerca de 144,000 episódios em março 2020. Discussão: Os resultados deste estudo preliminar estão alinhados à evidencia produzida em estudos de pandemias anteriores. Informação sobre a utilização da urgência e sobre características demográficas e clínicas dos episódios seriam relevantes para analisar esta redução. Conclusão: Verificouse um decréscimo significativo no número de urgências em março 2020, e apesar das causas desta redução não estarem ainda identificadas, é evidente a ligação entre o início da pandemia e a diminuição da procura. Entender este fenómeno é crítico para planear intervenções que evitem morbilidade ou mortes desnecessárias, causadas pelo atraso na ida à urgência.

C 2020 The Author(s). Published by S. Karger AG, Basel on behalf of NOVA National School of Public Health

Demand for Hospital Emergency Services

during the First Month of COVID-19

\section{Introduction}

The first confirmed case of COVID-19 in Portugal was registered on March 2, and by the last day of the month, the country had a total of 8,251 confirmed cases and 59,456 suspected cases, according to the Directorate General of Health reports [1]. The spread of the new agent SARS-CoV-2 (severe acute respiratory syndrome coronavirus 2 ) is associated with changes in health care utilization patterns in the Portuguese National Health Service (NHS).

Since emergency services are a central element of the health care provision structure, they are sensitive to external changes caused by epidemiological events, such as pandemics. During critical response periods, traditional emergency services characteristics change, with a natural prioritization to episodes with high severity and mortality. The increased pressure caused by a sudden, extensive, severe and new event is visible in a point-of-care setting that traditionally is under pressure per se due to its regular operation.

All over the world, there is an increasing demand for emergency care, registering an annual average growth rate of $2.4 \%$ over the past decade. In Portugal, however, this phenomenon is even more substantial: our country stands out as the major emergency services user per capita within the Organization for Economic Co-operation and Development (OECD). Indeed, Portugal registered over 70 visits per 100 habitants, significantly above the OECD average value of 31 per 100 habitants [2]. These figures classify Portugal as a country where there is an overuse (deemed inadequate) of emergency care.

The root causes of this phenomenon in developed countries are multiple, complex and interdependent. The most commonly identified are age and gender $[3,4]$, the coverage regime [5, 6], user income level [7], rural and urban areas [7], the geographic distance to health care services [8], continuity of care [7, 9], the availability of general practitioners (family doctors) [10], the lack of confidence in the general practitioner and the access to primary care (waiting time) $[4,11,12]$.

If on one hand there is an increasing and often excessive demand, on the other hand, the supply suffers from structural problems that prevent the best response to this type of demand. Altogether, human resources scarcity and lack of specialization (Portugal is one of the few countries without an emergency care specialization), old and functionally inappropriate facilities, service disarticulation, the inexistence of internal and external continuity of care in the clinical discharge, and the low-quality registries fos- 
ter the long waiting times, lack of efficacy and overall dissatisfaction with emergency care provision [13].

In this already complex scenario, the emergence of the COVID-19 pandemic creates new challenges and calls for distinct responses of the emergency services. Health authorities adopted several measures to foster health care service response, of which we highlight: (i) the organization of specific circuits for COVID-19-suspected patients, with alternative pathways that do not collide or overlap with the regular emergency care demand (for other reasons); (ii) the reinforcement of the phone support lines; (iii) the extension of service areas, such as tents or alternative areas; (iv) testing spaces as drive-in stations; (v) care provision in primary care units for mild cases; (vi) additional production contracting with private hospitals.

This pandemic also brings uncertain effects. One could expect a significant increase in the number of emergency episodes, as there was additional demand associated with this new disease on top of the regular service use. However, contrary to this expectation, previous studies related to the SARS pandemic showed a significant decrease in emergency care episodes. This trend was consistent across several countries, pointing out a maximum of $80 \%$ variation considering the previous production levels [14-16].

It is hard to determine the optimal level of health care service use. The opportunity cost that enables the release of resources for COVID-19 patient management, or even the likely decrease in inappropriate emergency episodes, may be a positive effect. However, there is a chance that health needs that should be fulfilled in the emergency service are not expressed, which may cause a problem in the short/medium term. The potential postponement of the expressed demand may have a direct impact on the health of the Portuguese population and cause an increase in disease that will need to be covered in a more severe format.

The moral conscience to avoid service overload (that is currently focused in the pandemic response), the movement restriction and social isolation/quarantine, the struggle in finding transportation or even the contamination risk avoidance are all relevant factors that can prompt the choice of not consuming emergency care services.

Hence, this study aims to analyze the use of emergency services during the first pandemic month, compared to historical records.

\section{Methods}

Data from emergency episodes in mainland Portugal, from January 2014 to March 2020, were downloaded from the NHS Transparency Portal: a website hosted by the Portuguese govern- ment, with monthly updates [17]. At the time of data collection, the Portal had not updated its information for March; therefore, we obtained the information on daily evolution for this month from the NHS monitoring website [18]. All data are publicly available.

Emergency episodes were analyzed according to two dimensions: geographic distribution and clinical priority. For geographic distribution, episodes were identified according to the Regional Health Administration (RHA) of mainland Portugal in which they occurred. For clinical priority, episodes were analyzed according to the classification of the Manchester Triage System (MTS) assigned at the emergency service. The MTS is one of the most common triage systems used in Europe, in which a health professional assigns a classification to the patient based on signs and symptoms. This classification indicates the urgency of the patient's situation and is represented by six colors ranging from less to more urgent: white (elective procedures), blue (nonurgent conditions, time to care must be $\leq 240 \mathrm{~min}$ ), green (standard conditions, time to care must be $\leq 120 \mathrm{~min}$ ), yellow (urgent conditions, time to care must be $\leq 60 \mathrm{~min}$ ), orange (very urgent conditions, time to care must be $\leq 10 \mathrm{~min}$ ) and red (emergency conditions, immediate care).

The evolution of emergency services from March through September 2020 was forecasted, considering the historical data from January 2014 to February 2020. This forecasting indicates the estimated number of episodes, assuming the time series followed the same patterns from February 2020 backwards, i.e. before cases of COVID-19 were confirmed in Portugal. The exponential smoothing algorithm used for this forecasting process estimates the new figures as a continuation of the previous values but accounting for seasonality.

Using the mean number of episodes for previous months and the estimated number of episodes obtained by the forecasting methods, the impact on emergency production levels for the first month of COVID-19 spread in Portugal globally was calculated by RHA and MTS classification. These values represent changes in the demand for emergency services. The Wilcoxon signed-rank test was used to evaluate whether there were significant differences between the mean number of emergency service use for the previous months and the observed values for March 2020, by RHA and MTS, with a 5\% significance level.

\section{Results}

Analyzing the time series of emergency service use in mainland Portugal between 2014 and 2019, there seems to be some homogeneity in values. In March 2020, 295,451 emergency episodes were registered, representing a $45 \%$ reduction concerning the previous 12 months. The number of emergency service use in March 2020 is outside the confidence interval for the forecasted values for March onwards, calculated with the time series (Fig. 1). This value is statistically different from the monthly average value for the 3 previous years, according to the MTS and RHA ( $p$ value $<0.001$ ) 
Fig. 1. Time series with observed and forecasted number of emergency service use, January 2014 to September 2021, Portugal.

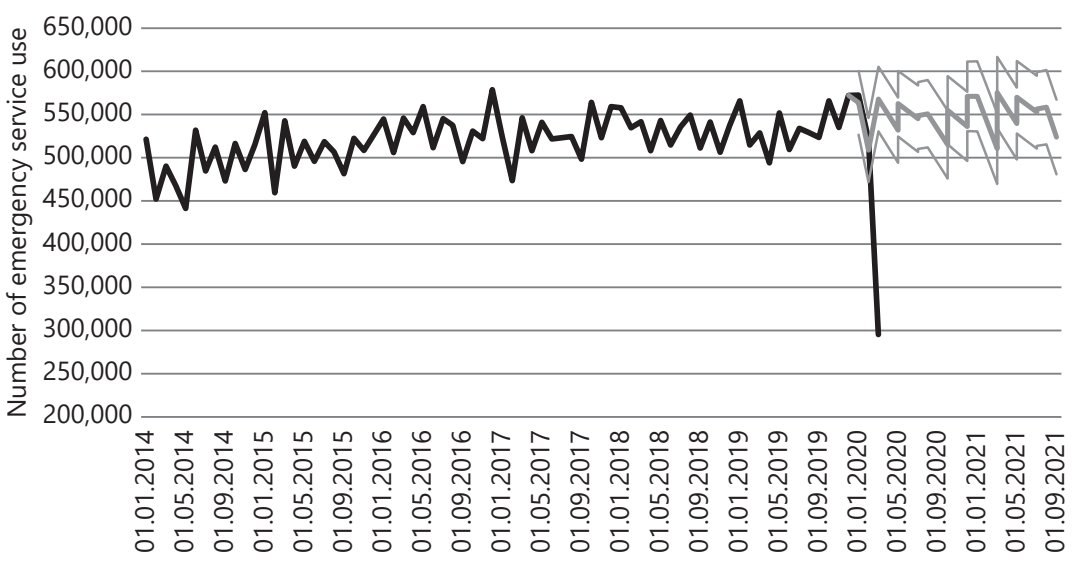

— Observed — Forecasted — Lower confidence limit — Upper confidence limit

Table 1. Number of forecasted and observed emergency service use, March 2020, Portugal

\begin{tabular}{lrrr}
\hline & $\begin{array}{c}\text { Forecasted emergency } \\
\text { service use March 2020 }\end{array}$ & $\begin{array}{l}\text { Observed emergency } \\
\text { service use March 2020 }\end{array}$ & $\begin{array}{l}\text { Difference forecasted - } \\
\text { observed (reduction in \%) }\end{array}$ \\
\hline Total & 567,963 & 295,451 & $272,512(47.98 \%)$ \\
\hline RHA & & & \\
Norte & 192,826 & 109,062 & $83,764(43.44 \%)$ \\
Centro & 99,619 & 51,649 & $47,970(48.15 \%)$ \\
Lisboa e Vale do Tejo & 211,131 & 99,772 & $111,359(52.74 \%)$ \\
Alentejo & 31,519 & 18,626 & $12,893(40.90 \%)$ \\
Algarve & 30,337 & 16,342 & $13,995(46.13 \%)$ \\
MTS & & & $33,786(59.69 \%)$ \\
No triage & 56,600 & 22,814 & $2,895(19.72 \%)$ \\
White & 14,682 & 11,787 & $2,456(31.04 \%)$ \\
Blue & 7,911 & 5,455 & $91,734(47.36 \%)$ \\
Green & 193,715 & 101,981 & $121,069(50.10 \%)$ \\
Yellow & 241,673 & 120,604 & $22,313(41.33 \%)$ \\
Orange & 53,984 & 1,671 & $558(32.88 \%)$ \\
Red & 1,697 & 1,139 & \\
\hline
\end{tabular}

In the analysis of the time series by geographic distribution, there is a reduction in the number of emergency service use observed in March 2020 for all RHA (Fig. 2).

Table 1 contains the characterization of the emergency service use in March 2020 in two categories: the real values observed (obtained from NHS data), and the forecasted values (obtained through the forecasting process). In total, there were 295,451 emergency episodes in mainland Portugal in the analyzed month; compared with the forecasted value, there was a $48 \%$ reduction in the number of emergency services used. In the analysis by RHA, Alentejo had the smallest decrease in the number of episodes, with around 12,000 fewer episodes than it was forecasted (41\% reduction). Lisboa e Vale do Tejo (LVT) presented the highest reduction both in absolute and percentual values, with 111,000 episodes less than it was forecasted (53\%). In the analysis by MTS, the elective episodes (white) had the smallest reductions in percentage; all other categories had reductions superior to $30 \%$. The episodes classified as yellow showed the high- 
Fig. 2. Time series with expected and forecasted number of emergency service use by RHA, January 2014 to September 2021, Portugal. LVT, Lisboa e Vale do Tejo.

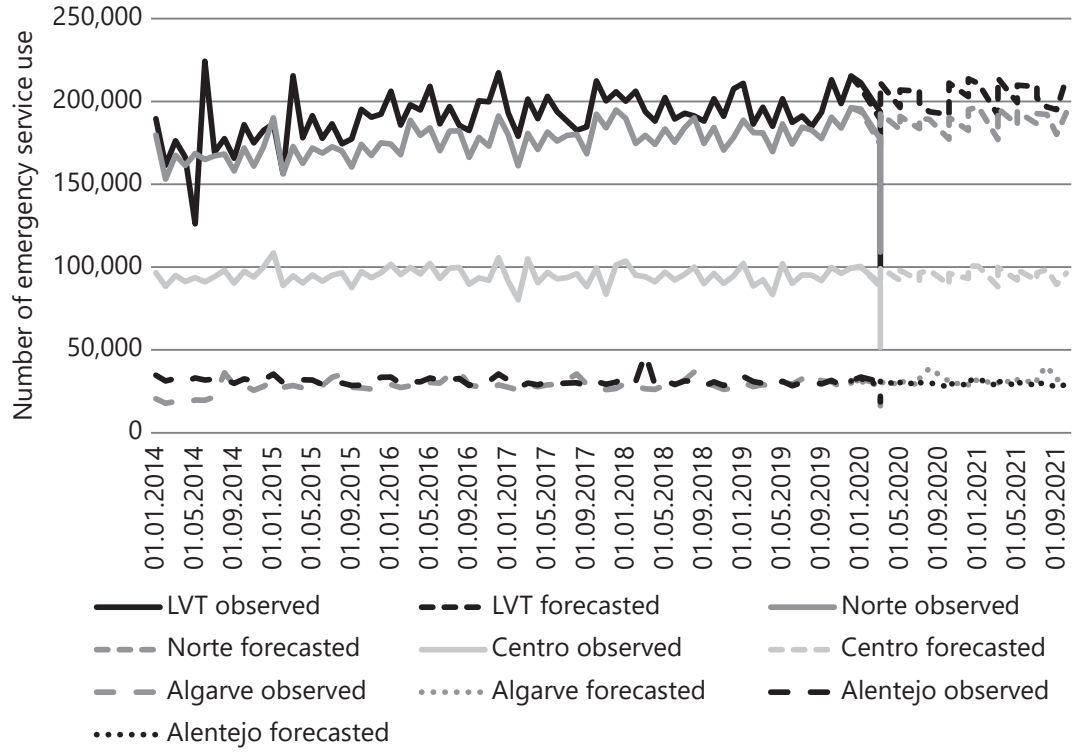

Fig. 3. Time series with expected and forecasted number of emergency service use by priority according to MTS, January 2014 to September 2021, Portugal.

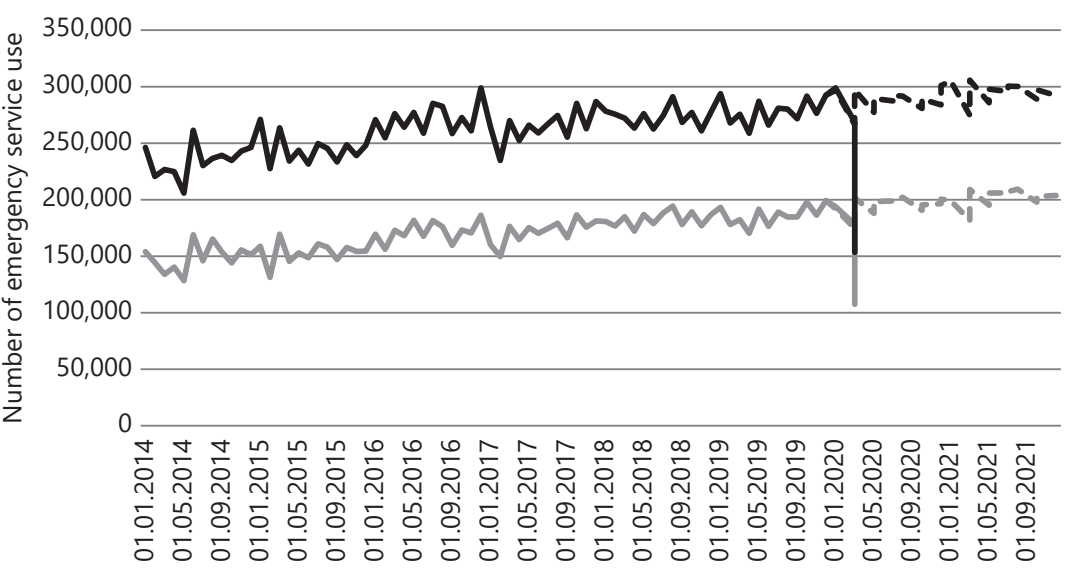

Nonurgent observed $\quad-\infty$ Nonurgent forecasted

- - - Urgent forecasted est decrease (50\%), which represents a difference of 121,069 episodes in relation to the expected value for this month.

In the analysis of the time series by MTS, the number of emergency services use in March 2020 sharply dropped both for nonurgent (blue and green) and urgent cases (yellow, orange, red) (Fig. 3). The number of emergency service use classified as urgent was lower than the number of nonurgent ones for the past 2 years.

\section{Discussion}

The spread of the SARS-CoV-2 changed the natural evolution of the use of emergency services in Portugal. The results show a reduction of $48 \%$ in the number of episodes registered in March 2020, compared to the expected figures. All RHA registered significant decreases, ranging from $43 \%$ in Alentejo to $53 \%$ in LVT. Interestingly, at the moment, Alentejo is also the area with fewer 
COVID-19 cases in mainland Portugal. Although the time that has elapsed since the start of the pandemic is still short, there is a similar trend to results obtained in the analysis of other pandemics, such as SARS, in other countries. The studies of Huang et al. [16] and Chen et al. [15] also show sudden and significant changes in the demand for emergency services, which varied between 30 and $80 \%$.

No significant differences were found between the colors of the MTS. All colors showed a reduction in the number of episodes in emergency services, between 30 and $50 \%$, a trend visible in all RHAs.

The causes of this reduction, however, are not yet determined, but the association between the beginning of the pandemic and the reduction of this demand is evident. Two hypotheses to explain the phenomena may arise: the first is that there is no manifestation of needs due to the fear of contamination at the point-of-care of hospital emergencies; the second is a natural reduction in the reasons that motivate going to emergencies, such as work and road accidents, sick leaves, colds and flu with minor symptoms, sports injuries, among others. These causes for hospitalization can be counterbalanced by other causes that will replace them. In essence, a longer stay at home due to recommended/mandatory physical isolation may cause a higher probability of domestic accidents, family violence, substance abuse and development of dependencies.

The reduction can also be a consequence of new procedures to diagnose patients infected with COVID-19; before the pandemic, patients with symptoms such as fever, cough and shortness of breath were assigned one of the MTS categories, according to the protocols, and treated on the emergency setting. Now, patients that present such symptoms are identified as potentially infected with COVID-19, and care for them is provided through a special pathway for suspected and confirmed cases of COVID-19. Therefore, the reduction might reflect the redirection of cases.

The shift of attention and resources from the NHS to the response to the COVID-19 pandemic also implies an opportunity cost, of not solving health problems that should be resolved during this period. The late or postponed action of health care could have significant implications in the near future. The accumulation of unmet or unresolved needs will imply higher levels of complexity and severity of the pathologies, increasing the health and economic risks associated with these characteristics.

Therefore, the communication of the actions taken, and the users' confidence gain is essential to ensure that those who effectively need to seek emergency services can do so without fearing an increased risk of contamination. Such action may avoid a larger problem in the future.

This study is carried out during the pandemic development and presents some limitations due to the current setting. First, there is a lack of information on the use of emergency services: demographic characteristics, main diagnoses and patients' comorbidities or their frequency of use that would allow to deepen the analysis and answer a broader set of questions. This analysis did not include the financial impact on hospital emergency services either.

The particular understanding about the characteristics of emergency episodes would be relevant to analyze the possible change suggested by the "disappearance" of about 144,000 urgent episodes (red, orange and yellow) during March 2020 (compared to the forecasted figures) that the authors identified using publicly available information.

Given the uncertainty of the future use of health services, will the upcoming situation be aggravated by the accumulation of disease stock that is postponed or will there be a more moderate and appropriate emergency behavior? It is not possible to accurately predict future scenarios, but in the short term, an altered behavior is expected given the traditional urgency use. In the study by $\mathrm{Chu}$ et al. [19], results showed that, although the SARS pandemic period lasted 3 months, the recovery time from previous average levels of use was gradual of 45,77 and $87 \%$ in the years that followed the historical demand.

Another study on the impact of SARS on emergency services in Taiwan found similar results to the ones identified for the current Portuguese situation: there was a peak of $51 \%$ reduction during the SARS epidemic, and this reduction was observed for all triage categories [16]. Studies produced in the SARS context recommended the development of management strategies to deal either with the re-emergence of SARS or other contagious diseases, taking into consideration both the immediate and the long-term effects of such outbreaks [16, 19].

In this study, only the emergency production was analyzed. There is also evidence of a significant deceleration in the demand for health care in other productions, namely in primary health care, and presently in all scheduled hospital activity that was cleared and postponed. This situation may translate in the future in additional use of emergency services - an open door to the health system - to attempt to respond more quickly to health problems that have not yet been resolved. 


\section{Conclusion}

The variation induced by unexpected events, such as pandemics, may result in significant effects in health services. An initial analysis of the evolution of emergency services volume and profile in Portugal, after the first month of this pandemic, highlights a substantial and statistically significant decline (aligned with the existing literature on similar events). For this purpose, the number of emergency episodes in March 2020 was compared to the average number of monthly episodes of the past years (since 2014). The analysis was also performed at both RHA and MTS classification levels.

Amongst the positive effects, there is a decrease in nonurgent episodes (particularly the green ones). However, the similar decrease registered in the urgent episodes (such as yellow cases) may represent a substantial risk for the future use of health care services, as these problems will remain unresolved and increase in severity in the future.

This analysis needs to be further detailed, considering all other variables that will enable a better understanding of the current phenomenon. The uncertainty on the future evolution will remain, but the recommendation of not postponing necessary health contacts seems crucial to avoid more severe problems for both Portuguese users and the NHS capacity in the future.

\section{Disclosure Statement}

The authors have no conflicts of interest to declare.

\section{Funding Sources}

This project was performed without funding.

\section{References}

1 Portugal Ministério da Saúde, DGS. Relatório de situação epidemiológica em Portugal. Lisboa: Direcção Geral da Saúde; 2020.

2 Berchet C. Emergency care services: trends, drivers and interventions to manage the demand. Paris: OECD Publishing; 2015. OECD Health Working Papers vol 83.

3 Reeder T, Locascio E, Tucker J, Czaplijski T, Benson N, Meggs W. ED utilization: the effect of changing demographics from 1992 to 2000. Am J Emerg Med. 2002 Nov;20(7):583-7.

4 Rust G, Ye J, Baltrus P, Daniels E, Adesunloye B, Fryer GE. Practical barriers to timely primary care access: impact on adult use of emergency department services. Arch Intern Med. 2008 Aug;168(15):1705-10.

5 Weber EJ, Showstack JA, Hunt KA, Colby DC, Callaham ML. Does lack of a usual source of care or health insurance increase the likelihood of an emergency department visit? Results of a national population-based study. Ann Emerg Med. 2005 Jan;45(1):4-12.

6 Hampton T. The ED and the uninsured. JAMA. 2004;292(12): 1419 .

7 Ionescu-Ittu R, McCusker J, Ciampi A, Vadeboncoeur AM, Roberge D, Larouche D, et al. Continuity of primary care and emergency department utilization among elderly people. CMAJ. 2007 Nov;177(11):1362-8.
8 Chen BK, Cheng X, Bennett K, Hibbert J. Travel distances, socioeconomic characteristics, and health disparities in nonurgent and frequent use of hospital emergency departments in South Carolina: a population-based observational study. BMC Health Serv Res. 2015 May; 15(1):203.

9 Schoen C, Osborn R, Doty MM, Bishop M, Peugh J, Murukutla N. Toward higher-performance health systems: adults' health care experiences in seven countries, 2007. Health Aff (Millwood). $2007 \quad$ Nov-Dec; 26(6 Suppl2):w717-34.

10 Carret ML, Fassa AC, Domingues MR. Inappropriate use of emergency services: a systematic review of prevalence and associated factors. Cad Saude Publica. 2009 Jan;25(1):7-28.

11 Puig-Junoy J, Saez M, Martínez-García E. Why do patients prefer hospital emergency visits? A nested multinomial logit analysis for patient-initiated contacts. Health Care Manage Sci. 1998 Sep;1(1):39-52.

12 McCusker J, Karp I, Cardin S, Durand P, Morin J. Determinants of emergency department visits by older adults: a systematic review. Acad Emerg Med. 2003 Dec;10(12):1362-70.
13 Portugal,. Ministério da Saúde, GT-SU. Relatório do Grupo Trabalho Serviços de Urgência (GT-SU). Lisboa: GT-SU; 2019.

14 Chen WK, Cheng YC, Chung YT, Lin CC. The impact of the SARS outbreak on an urban emergency department in Taiwan. Med Care. 2005 Feb;43(2):168-72.

15 Chen WK, Wu HD, Lin CC, Cheng YC. Emergency department response to SARS, Taiwan. Emerg Infect Dis. 2005 Jul;11(7): 1067-73.

16 Huang HH, Yen DH, Kao WF, Wang LM, Huang CI, Lee CH. Declining emergency department visits and costs during the severe acute respiratory syndrome (SARS) outbreak. J Formos Med Assoc. 2006 Jan;105(1):31-7.

17 Portugal, SNS-Serviço Nacional de Saúde. SNS Portal transparência [Internet]. Lisboa: Serviço Nacional de Saúde; 2019 [cited 2019 Mar 28]. Available from: https://www.sns. gov.pt/transparencia/

18 Portugal, SNS-Serviço Nacional de Saúde. SNS - Serviços de Urgência [Internet]. Lisboa: Serviço Nacional de Saúde; 2019 [cited 2019 Mar 28]. Available from: https://www. sns.gov.pt/monitorizacao-do-sns/servicosde-urgencia/

19 Chu D, Chen RC, Ku CY, Chou P. The impact of SARS on hospital performance. BMC Health Serv Res. 2008 Nov;8(1):228. 